deviate, there is danger of his losing caste, and being frowned upon by those whose dictum is Judex in high places; and never, till each physician has independence enough to use his own judgment, in the treatiment of disease, can the profession hold up in its front the motto "Excelsior," and be progressive.

\title{
ASIATIC CHOLERA.
}

[Commuricated for the Boston Medical and Surgical Journal.]

Probably almost every physician on the approach of cholera the present season, asked himself the question, what remedy shall I give in the cases that may come under my care? The subscriber marked out a course for himself at the onset, and here it is, with the result :-Calomel, 20 grains; this arrested vorniting, and was retained in the stomach, with one exception, where the dose was repeated, and then retained; from 1 to 2 grs. calomel administered every hour or two, till the bowels were operated upon by the medicine. Mustard was also applied at the beginning, over the stomach and liver, and the feet put into warm water. The patient was allowed ice water to drink, one hour after the first dose of calomel was given. Calomel has a three-fold effect in cholera ; 1st, to arrest the vomiting ; 2d, to carry off foul or indigested matter; and, 3d, to cause a secretion of bile, which is always arrested in cholera. Four sevenths of the patients treated as above, recovered ; and in every case where a secretion of bile was manifest in the stools, recovery followed.

Henry Russele, M.D.

Providence, R. 1., 9th mo. 11 th, 1854.

THE BOSTON MEDICAL AND SURGICAL JOURNAL.

BOS TON, SEP TEMBER $20,1854$.

Education of Idiots.-Until within a few years, it was supposed that any attempt to improve the condition of idiots, by a system of culture or training, would be entirely useless. But it has been fully demonstrated, that they are susceptible of being greatly improved in their mental, as well as physical condition, and the attention of philanthropists has been directed to the procuring of means to establish schools for this unfortunate class of beings. The Massachusetts Sehool for Idiotic and Feeble-minded Youth, located in this city, which is now under the patronage of the Commonwealth, was, we believe, instituted mainly through the efforts of Dr. S. G. Howe, its president and superintendent. Under his fostering care, it seems to have accomplished, thus far, all that its most sanguine friends und supporters could expect or wish for. It now numbers forty-two pupils, thirty-one of whom are State beneficiaries, and the other eleven private pupils. Dr. Howe, in his admirable report for the present year, says that "one of the lessons learned by experience in this school is, not to rely upon first appearances; to promise little; to hope ever; to despair never. There are cases which defy calculation; for while some that seemed to promise most at first sight 